\title{
Soft-Sensing in Batch Annealing Based on Finite Differential Method and Support Vector Regression
}

\author{
Ján Kačur ${ }^{1 *}$, Milan Durdán', Marek Laciak' ${ }^{1}$ Patrik Flegner ${ }^{1}$ \\ 1 Technical University of Košice, Faculty BERG, Institute of Control and Informatization of Production Processes, \\ Němcovej 3, 04200 Košice, Slovak Republic \\ * Corresponding author's e-mail: jan.kacur@tuke.sk
}

\begin{abstract}
The temperature of annealed steel coils is a determining variable of the future steel sheets quality. This variable also determines the energy consumption in operation. Unfortunately, the monitoring of coil inner temperature is problematic due to the furnace environment with high temperature, coil structure, and annealing principle. Currently, there are no measuring principles that can measure the temperature inside the heat-treated product in a non-destructive manner. In this paper, the soft sensing of inner temperature based on the theory of non-stationary heat conduction and approach based on Support Vector Regression (SVR) was presented. The results showed that a black-box approach based on the SVR could replace an analytic approach, though with lesser performance. Several annealing experiments were performed to create a training data set and model performance improvement in the estimation of inner coil temperatures. The proposed software based on non-stationary heat conduction can calculate the behavior of inner coil temperature from the measured boundary temperatures that are measured by thermocouples. The soft-sensing principles presented in this paper were verified under laboratory conditions and on the data obtained from a real annealing plant.
\end{abstract}

Keywords: annealing, steel coil, temperature measurement, soft-sensing, finite differences method, support vector regression.

\section{INTRODUCTION}

The quality of the steel products and its expensiveness is the determining the criterion for successfully more-competitive of steel production company. In various types of annealing, the temperature of the annealed steel coils is the main variable that determines the quality of product and energy consumption. When the temperature is too high, there is a useless cost of energy. On the other hand, the required product quality may not be obtained. Various sensors measuring the surface temperatures of the massive product exist, but for the non-destructive measuring of inner temperatures, only model-based soft-sensors can be used. The existence of such sensors would enable effective control of the quality of temperature behavior in real-time and the development of new methods of process control with a great time delay. This paper presents a theoretical background that was used for soft-sensor modeling and verification of the proposed models on the operational data. The aim was to propose the software model able to estimate the temperatures inside a steel coil based on the measured boundary temperatures. These inner temperatures were measured by thermocouples only for the soft-sensing verification. The authors of this paper also developed the techniques for soft-sensing boundary coil temperatures based on the temperature of annealing atmosphere in a bell furnace $[8,10]$. The second method that was verified to soft-sensing of inner coil temperatures is based on machine learning. Support Vector Regression (SVR) was used as a part of Support Vector Machines (SVMs). The results from black-box machine model will be compared with the proposed analytical model in this paper. The proposed approaches should be possible to apply 
in the online measurement of inner temperatures and obtain a better insight into the process behavior. In this paper, the results from experimental measurements and simulations are provided.

\section{Understanding batch annealing}

Bell furnaces are widely used for annealing of steel coils. The coils can be of steel strips, a steel wire or any other shape which can be loaded into the furnace. The furnace can be electrically heated, oil-fired or gas-fired. It can also be used for decarburizing of stampings. A bell-type furnace (see Figure 1) is a versatile furnace suitable for black, bright and spheroid annealing of steel and non-ferrous strips, wires and general heat treatment processes up to $1100^{\circ} \mathrm{C}$.

The furnace is of a cylindrical furnace in top hood design that involves the furnace kept on the fixed bases in the inverted position. In metallurgy and materials science, annealing is a heat treatment that alters the physical and sometimes chemical properties of a material to increase its ductility and reduce its hardness, making it more workable $[1,6]$. It involves heating a material above its recrystallization temperature, maintaining a suitable temperature, and then cooling it. The three stages of the annealing process that pro-

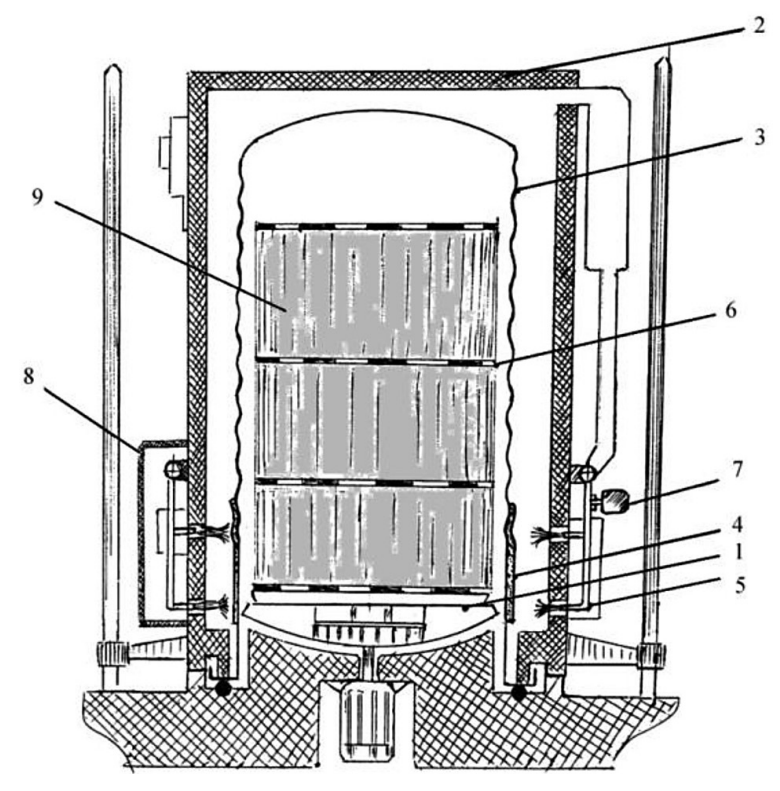

Fig. 1. Scheme of bell furnace (modified after [1]): 1 - stand, a 2 - heating cap, 3 - muffle in which there are pads, 4 -pads in the form of combustion catalysts located in the combustion zone, 5 - burners, 6 convection rings, 7 - controls the fuel supply, 8 - the recuperative oxidizer and fuel, 9 - steel coil ceed as the temperature of the material increased are recovery, recrystallization, and grain growth. The impact of annealing temperature and annealing atmosphere on the grain growing was well analyzed in $[12,30]$.

Bell furnaces comprise the stand, the heating hood, muffle, convector rings, and burners; on the surface of the muffle there is a lining in the form of combustion catalysts installed in the area of burners. The bell-type furnace catalytic combustion has high efficiency and environmental cleanliness of combustion. The principle of the furnace cover the following: in the initial period of the burner is heated pads to a certain temperature, then shuts off the fuel supply and the burner is transferred into the mode of catalytic combustion. The gaseous fuel with the oxidizer (i.e., air) is heated in the heat exchanger, served on hot plates made in the form of catalysts with flameless combustion of the fuel, characterized by high environmental performance and the effective use of heat [33].

Three or four coils are stacked on top of each other, separated by convector plates, in a bellshaped furnace. The inner cover is placed over the coils and its volume filled with an inert gas to prevent the coils from oxidizing under the high temperatures. The outer furnace cover is put in position. Burners are fired tangentially at the inner cover causing it to heat up. The heat from this cover is radiated to the coils causing them to heat up too. Then coils are held, or soaked, at a temperature of around $650^{\circ} \mathrm{C}$. Further, these coils are left to cool to the room temperature. The required temperature was achieved through the coil, long heating, soaking and cooling times [5].

Recrystallization of the deformed structure begins to take place at the temperatures around $550^{\circ} \mathrm{C}$. This is done through nucleation and growth of the nuclei. This process uses the

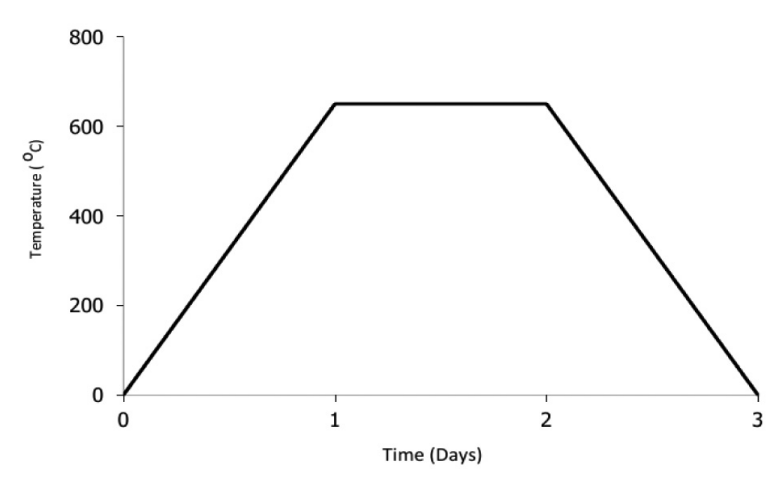

Fig. 2. Typical batch annealing cycle 


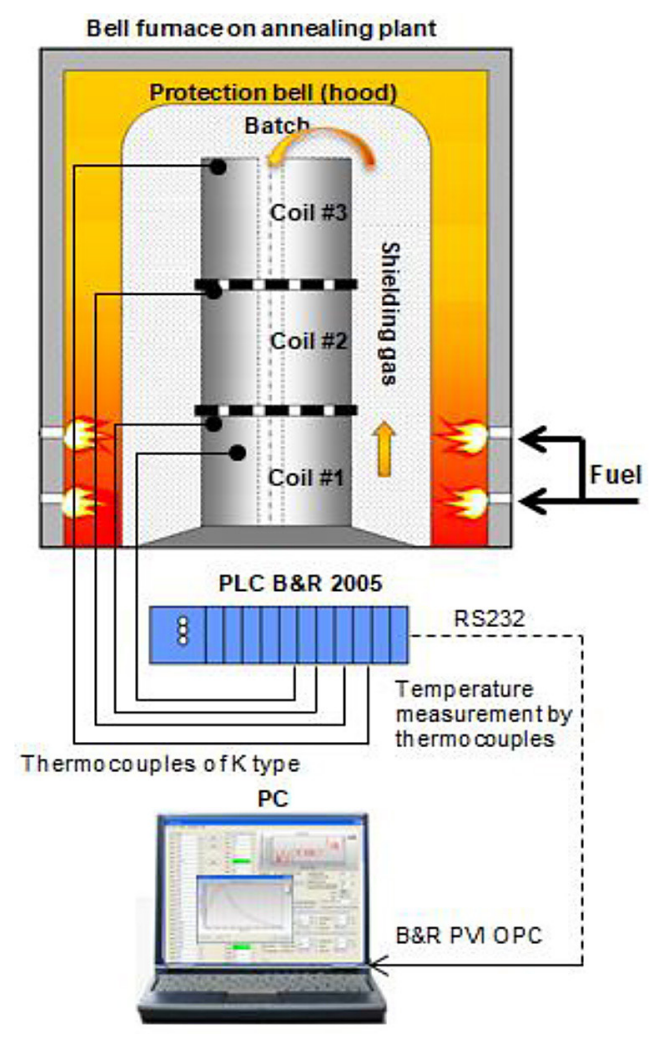

Fig. 3. Measuring chain in experimental annealing

stored energy within the grains and reduces the dislocation density [24].

A typical batch annealing cycle is shown in Figure 2. The cooling rate can be adjusted so that some carbon will remain in solid solution [6].

Figure 3 shows the basic scheme of temperature measurements on the bell furnace where experimental annealing was performed. Thermocouples of K-type, Programmable Logic Controller (PLC), and PC were used in measuring chain based on RS232 and communication protocol OPC (i.e., Open Platform Communication). The authors of this paper have created their own program for recording and displaying of measured temperatures., The measurements of coil temperatures using thermocouples were also checked for the verification of the indirect measurement based on the soft-sensor. For these check measurements, thermocouples were placed between windings of the given coil.

\section{Overview of soft-sensing in annealing}

In general, two types of steel strip annealing are processed in industry, i.e., batch type annealing where steel strips are rolled into coils and annealed in a bell furnace and continuous annealing where steel strips are passed thought the annealing line. In literature, various modeling approaches can be found. Studies are aimed especially at the prediction of final properties of annealed steel. They have primarily applied the laws of nonstationary heat conduction and neural networks (NNs). Much research work with non-stationary heat conduction in batch annealing has been done by Kostúr et al. [23]. The authors created an intelligent system of soft-sensing inner temperatures of steel coil annealed in a bell furnace.

Haouam et al. [14] have proposed a numerical model of the temperature distribution of steel coils during annealing process on differential equations of heat conduction. The resolution is performed with the method of finite differences. Thermal coefficients used in the model were adjusted by the simplex optimization technique. The modeling results show good agreement with the experimental measurements.

Durdán et al. [10] and Kostúr [21] proposed the system of soft-sensing temperatures in the annealing process based on the rules of non-stationary heat conduction. Basically, on the temperature of protection atmosphere measured by a thermocouple, the system calculates the temperatures on the surface and inside of the annealed batch. The system of soft-sensing was verified using operational measurements obtained on the annealing plant. The surface temperatures of the steel coil that was experimentally annealed were modeled by a regression model and its inner temperature by differential equations of heat conduction. Moreover, the comparison of the proposed analytical model with neural network (NN) was performed in this paper. The model of heat flows to estimate the surface temperature of the annealed steel coil was proposed in [8]. The modeling of the batch annealing process based only on neural network was initially published in [28].

The paper [11] describes the design of a physical model of the bell furnace, the task of which is to explore the process of annealing of steel coils for optimization. Optimization covers the the research on the annealing regimes in a selected type of furnace atmosphere and the design of the measuring sensors for the purpose of verification of soft-sensing system of temperatures in the batch. In this paper, the physical model of bell furnace and heat flow sensor was proposed. Wigley [34] has developed a model to predict the final properties of continuous annealed steel. The actual process data, along with the mechanical properties 
derived using tensile testing were used to create the model. A generalized regression network was used as the main predictive mechanism. Saraee et al. [29] modeled the batch annealing process, i.e., prediction of heating and cooling time and trend prediction of coil core temperature. The modeling of the annealing process was carried out by using the data mining techniques and backpropagation NN. A good correlation between the results of NN method and the results of thermal models has been obtained in this work. The authors have used two regression models, one for heating and the second for cooling. The parameters of the regression function were estimated by NN. Further examples of the use of NNs in annealing can be found in $[2,4,7,13,15,16,17]$.

Overfitting was identified as a potential problem associated with NNs, where the model fits the training data but not further data. It was suggested that to overcome this data should be divided into the training and test data, with the training data used to make the model and the test data used to validate this model [34]. The back-propagation NNs are capable of representing the general nonlinear functions, but their disadvantage is often very difficult to teaching, because practically there is always a risk of deadlock in the local minimum of the error function, and in addition, learning is highly complicated by looking for a high number of weights in the multidimensional space. An alternative and a relatively new approach involve the so-called Support Vector Machines (SVMs). The SVMs are used for time series prediction and classification tasks. These methods represent the field of the so-called kernel machines and exploit the benefits provided by effective algorithms for finding a linear boundary while being able to represent highly complex non-linear functions. The kernel functions methods try to find an optimal linear separator. The optimal linear separator in SVMs algorithm is searched using the quadratic programming method. In literature, there is only low evidence of Support Vector Machines within the steel industry and especially in steel annealing. Some application of SVR can be found in [19] and [20].

\section{Experimental annealing in a laboratory furnace}

In this paper, a bell furnace used for annealing coils and heated by gas was considered. A physical model of steel coil was created for this furnace where annealing is provided by electric spirals (see Figure 4). Several experiments of temperature measurements on a real annealing plant were also performed using PLC and PC.

Annealing was carried out on a model of steel coil with thermocouples which was placed on spirals (i.e., control temperatures measurement), in the coil surface (i.e., boundary temperatures measurement) and in the coil (i.e., check measurement of inner temperatures). The experimental annealing was used in the research on the softsensing system of inner temperature in steel coil with the application on a real bell furnace and real annealing. It was not possible to control the furnace continually by the change of electric power (400 VAC). For this reason, only digital signal (24 VDC) was used for control of heating (switch on/off of spirals) and constant supply power. In [11] and [18], the theoretical background of the proposed control system implemented on PLC (B\&R 2005) has been presented. The control algorithm performs the pulse width modulated (PWM) control in cooperation with PI controller and ON-OFF control of the heating [18]. The PLC was connected to PC through Bernecker \& Rainer Process Variable Interface (B\&R PVI) and OPC. The monitoring system is possible to control heating according to the temperatures measured by thermocouples and placed on electric spiral or by inner coil temperatures estimated by soft-sensor (i.e., by a model).

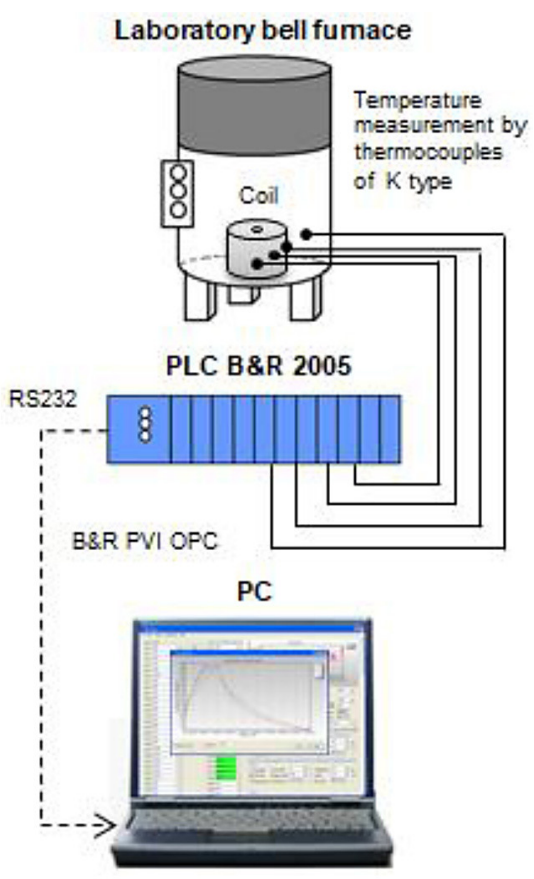

Fig. 4. Experimental bell furnace 


\section{UNDERSTANDING OF MODELING METHODS}

In this section, two methods that can be used for soft-sensing temperatures in an annealed coil were explained. The first method is based on the theory of non-stationary heat conduction and the second method - on support vector regression. While the first method is based on an analytical approach, the second one draws on the principle of the black box and machine learning.

\section{Nonstationary heat conduction modeling}

The starting point for creating the mathematical model was the Fourier-Kirhhoff differential equation of heat conduction (1).

$$
\frac{\partial T}{\partial \tau}=a\left(\nabla^{2} T+\frac{i_{Q_{v}}}{\lambda}\right)
$$

where: $a=\lambda /(c \cdot \rho)$ represents thermal diffusivity, which characterizes the rate of temperature change in the substance $\left(\mathrm{m}^{2} \cdot \mathrm{s}^{-1}\right)$. In an analysis of heat conduction, thermal diffusivity is the thermal conductivity divided by density and specific heat capacity at constant pressure. The parameter $\lambda$ is the thermal conductivity that depends on the type of material $\left(\mathrm{Wm}^{-1} \cdot \mathrm{K}^{-1}\right), c$ represents specific heat capacity $\left(\mathrm{J}^{\mathrm{kg}} \mathrm{kg}^{-1} \mathrm{~K}^{-1}\right)$, $\rho$ represents the density of the substance $\left(\mathrm{kg} \cdot \mathrm{m}^{-3}\right) ; T$ is the temperature $(\mathrm{K}) ; \tau$ is the time (s); $i_{Q_{V}}$ is an internal heat source $\left(\mathrm{W} \cdot \mathrm{m}^{3}\right) ; \nabla$ is Hamilton's operator; $\nabla^{2} T$ represents the second derivation of the temperature by spatial coordinates [31].

If the heat is generated or is consumed in the object, the power of internal heat sources $i_{Q_{V}}$ is determined for the unit of volume $\left(\mathrm{W} \cdot \mathrm{m}^{3}\right)$. In the absence of internal heat sources, i.e. $i_{Q V}=0$, Fourier differential equation of heat conduction for a temperature field in a rigid object without a heat source can be obtained as the following:

$$
\frac{\partial T}{\partial \tau}=a \nabla^{2} T=a\left(\frac{\partial^{2} T}{\partial x^{2}}+\frac{\partial^{2} T}{\partial y^{2}}+\frac{\partial^{2} T}{\partial z^{2}}\right)
$$

The left side of equation (2) (i.e., the partial derivation of temperature $T$ according to time $\tau$ ) is for time-stable temperature processes zero (i.e., stationary heat conduction). Equation (2) is a partial differential equation of the second order with the right side. Its solution is also for $i_{Q V}=0$ also complex for geometrically simple objects. This equation can be solved using the numerical meth- ods, the essence of which is to divide the object to the desired number appropriately of selected planar or spatial sections (i.e., elements), the substitution of derivations by the ratio of differentiation and deriving formulas for tracking heat conduction between elements (i.e., method finite element method, finite difference method, boundary element method).

The principle of all numerical methods is that a continuous change of all variables, found in the heat equation (2) is replaced by a discontinuous change. Thus, the infinitely small increments of variables (i.e., differentials) are replaced by the finite increments (i.e., differences). For such a procedure, the volume of the considered body is divided into a larger number of elementary volumes whose form depends on the selected coordinate system. In the method of finite differences, the area in which the Fourier equation of heat conduction is solved, a grid composed of a finite number of nodes will be covered. In these nodes, the value of derivation is substituted by the difference, i.e. the interpolation polynomial is replaced by several nodes of the grid, and their derivations are calculated. This creates a differential equation that is solved with known algebraic methods.

The most used types of grids include square, rectangular, polar hexagonal. The resulting model for the soft-sensing is based on the direct temperature measurement (i.e., contact measurement) of the surface by thermocouples (i.e., boundary temperatures) and solving the Fourier partial differential equation of heat conduction (2). Two variants of the two-dimensional solution of this model were developed, differing by the solution method of Fourier equation.

\section{Finite differences method}

The explicit application of finite differences method was used to solve equation (2) numerically. The problem of modeling non-stationary heat conduction in a 3D object (i.e., the steel coil) was simplified to model the heat conduction only in a 2D matrix, i.e., a rectangular cross-section of the coil. The aim was to solve the mathematical model of 2D object heat conduction. For this reason, equation (2) was considered in the following form:

$$
\frac{\partial T}{\partial \tau}=a \nabla^{2} T=a\left(\frac{\partial^{2} T}{\partial x^{2}}+\frac{\partial^{2} T}{\partial y^{2}}\right)
$$

at boundary conditions of the 1st type

$$
T_{s}=f(x, y)
$$




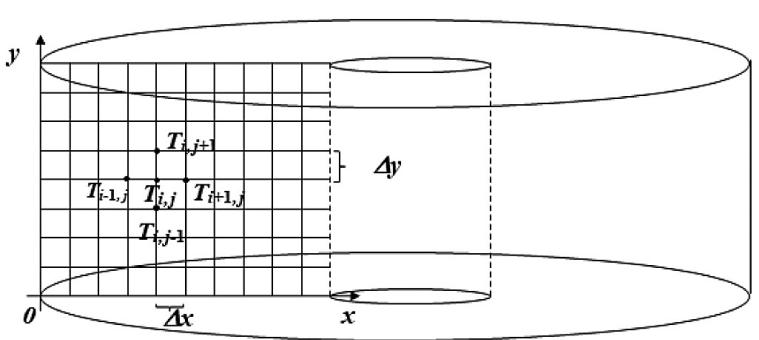

Fig. 5. The scheme of coil grid parameters

and initial conditions

$$
T_{I}(x, y)=f(x, y, 0)
$$

where: $T_{S}$ is the surface temperature of the object and $T_{I}$ is the object temperature at time $\tau=0$ [31].

The considered body is a steel coil. The mathematical model (3) is solved with the grid method in the $x, y$ coordinate system. On the given the object (i.e., in the cross-section of the coil), a grid consisting of parallel lines with the co-ordinate axes at a distance of $\Delta x$ and $\Delta y$ was created (see Figure 5).

The intersection points are called nodes (i.e., node points). The temperature at nodes is unambiguously defined by the following indices:

- $i$ is an index of the node in the direction of the $x$ axis, i.e., $x=i \cdot \Delta x$ for $i=1,2, \cdots, N$;

- $j$ is an index of the node in the direction of the $y$ axis, i.e., $y=i \cdot \Delta y$ for $i=1,2, \cdots, M$;

- $k$ is an index of the time step i.e., $\tau=k \cdot \Delta \tau$ for $k=1,2, \cdots, n$,

where $M$ is the total number of nodes on $x$ axis, $N$ is the total number of nodes on $y$ axis, and $n$ is the total number of simulation time steps.

Then $T_{i, j, k}$ represents the temperature at the node that lies on the intersection of the $i$-th parallel line with the $x$-th coordinate and the $j$-th parallel line with $y$ coordinate at time $\tau=k \cdot \Delta \tau$. For a small step grid (i.e., with low values of $\Delta x, \Delta y$, $\Delta \tau)$, the following is valid:

$$
\begin{aligned}
& \frac{\partial T}{\partial \tau} \cong \frac{T_{i, j, k+1}-T_{i, j, k}}{\Delta \tau} \\
& \frac{\partial T^{+}}{\partial x} \cong \frac{T_{i, j, k}-T_{i-1, j, k}}{\Delta x}
\end{aligned}
$$

and analogously in direction of the y-axis

$$
\frac{\partial^{2} T}{\partial x^{2}} \cong \frac{\frac{\partial T^{+}}{\partial x}-\frac{\partial T^{-}}{\partial x}}{\Delta x^{2}}=\frac{T_{i+1, j, k}+T_{i-1, j, k}-2 T_{i, j, k}}{\Delta x^{2}}
$$

$$
\frac{\partial^{2} T}{\partial y^{2}} \cong \frac{T_{i, j+1, k}+T_{i, j-1, k}-2 T_{i, j, k}}{\Delta y^{2}}
$$

By substituting equations (6), (9) and (10) into equation (3) and after algebraic modification, the final model (11) can be obtained.

$$
T_{i, j, k+1}=\left(1-\frac{2 a \cdot \Delta \tau}{\Delta x^{2}}-\frac{2 a \cdot \Delta \tau}{\Delta y^{2}}\right) \cdot T_{i, j, k}+\frac{a \cdot \Delta \tau}{\Delta x^{2}}\left(T_{i-1, j, k}+T_{i+1, j, k}\right)+\frac{a \cdot \Delta \tau}{\Delta y^{2}}\left(T_{i, j-1, k}+T_{i, j+1, k}\right)
$$

This equation is used to calculate temperatures at the nodal points of the coil at any time step $k$. On the basis of equation (11), the temperature at any node point in the next time step can be calculated (i.e., if the temperatures at the nodal points by which the point is surrounded in the previous time step are known). A closer analysis of equation (11) shows that its first term in brackets causes divergence in calculations if it takes negative values. Due to the stability of the solution, it is necessary to calculate the time step from the condition of stability (13) for the selected sections $\Delta x$ and $\Delta y$. The duration of the time step is determined from the stability condition, which in equation (11) provides the physical sense of the solution. The following applies for the stability condition [22]:

$$
1-\frac{2 a \cdot \Delta \tau}{\Delta x^{2}}-\frac{2 a \cdot \Delta \tau}{\Delta y^{2}} \geq 0
$$

then

$$
\Delta \tau \leq \frac{1}{2 a\left(\frac{1}{\Delta x^{2}}+\frac{1}{\Delta y^{2}}\right)}
$$


The equation (13) can be used in the simulation for estimation of time step $\Delta \tau$. The condition of stability (12) from which the value of the parameter $\Delta \tau(13)$ is determined, is checked in the calculation of each node. Similarly, the explicit equation for calculating the temperature field and time step can be derived for the three-dimensional solution of the heat conduction by introducing the $\Delta z$ parameter in the $z$-axis direction.

\section{Temperature modeling based on Support Vector Regression (SVR)}

In the application of SVR on annealing process, the basic idea is to map the temperature dataset $T$ to the high-dimensional feature space through non-linear mapping $\Phi$ and to perform linear regression in this space [3, 32]. In general, the input data set represents a vector of observations $x=\left(x_{1}, x_{2}, \ldots, x_{l}\right)$ and vector of targets $y$.

The usage can be found when the patterns of the training data $x$ are not linearly separable. The patterns are mapped by function $\Phi$ to another space where they can be separable. In application on annealing of steel coil, the input dataset represents the vector of "directly" measured temperatures $T=$ $\left(T_{1}, T_{2}, \ldots, T_{1}\right)$, i.e., measured by contact with thermocouples and responded measured outputs $y$, i.e., target inner temperatures. If a regression with one output variable is considered, the observations on the examined object can be written as a sequence of pairs $\left(T_{1}, y_{1}\right), \ldots,\left(T_{i}, y_{i}\right), \ldots,\left(T_{1}, y_{l}\right), T_{i} \in R^{n}$, $y_{i} \in R$. The vector $T_{i}$ represents one pattern of input observations (i.e., coil boundary temperatures) $T_{i}=\left(T_{i 1}, T_{i 2}, \ldots, T_{i n}\right)$. In order to create pairs for the training phase, the targets have to be measured by some way (i.e., several measurements of inner temperatures by thermocouples). Thus, the linear regression in the high-dimensional feature space corresponds to the non-linear regression in the low dimensional input space $R^{n}$. The prediction $f(T)$ from the pattern $T$ can be mathematically written as dot products in the low-dimensional input space as the following [27]:

$$
f(\mathbf{T})=\sum_{i=1}^{l}\left(\alpha_{i}-\alpha_{i}^{*}\right)\left(\Phi\left(\mathbf{T}_{i}\right) \cdot \Phi(\mathbf{T})\right)+b=\sum_{i=1}^{l}\left(\alpha_{i}-\alpha_{i}^{*}\right) k\left(\mathbf{T}_{i}, \mathbf{T}\right)+b
$$

where: $l$ is the number of patterns $\left(T_{1}, T_{2}, \ldots, T_{l}\right)$, parameter $b$ represents the limit value or the so-called threshold and parameters $\alpha_{i}, \alpha_{i}^{*}$ have an intuitive interpretation as the forces of pull or push of $f\left(T_{i}\right)$ to $y_{i}$ measurement. If considering two points $T_{i} T_{j}$, then the function that returns the scalar product between their images in high-dimensional feature space is known as the kernel function. In equation (14), the kernel function $k\left(T_{i}, T_{j}\right)=\left(\Phi\left(T_{i}\right) \cdot \Phi\left(T_{j}\right)\right)$ is established. In this paper the Gaussian kernel, i.e., function $k\left(T_{i}, T_{j}\right)=e^{-\gamma / T T-T j} \|^{2}(\gamma$ represents the sensitivity of the kernel function) and linear kernel, i.e., $k\left(T_{i}, T_{j}\right)=T_{i}^{T} T_{j}$ were used. The application of polynomial kernel, i.e., $k\left(T_{i}, T_{j}\right)=\left(\gamma\left(T_{i}^{T} T_{j}+1\right)\right)^{d}(d$ is an integer $)$ fails in the training phase.

When creating the SVR model, the kernel matrix $K=\left(k\left(T_{i}, T_{j}\right)\right)_{i, j=1}^{1}$ is usually used. It is the symmetric, positively defined matrix that specifies scalar products between all the pairs of points $\left\{T_{i}\right\}_{i, j=1}^{1}$. If the kernel matrix is calculated, there is no further need for a kernel function or implicitly defined mapping $\Phi$ nor coordinates of the points $\Phi\left(T_{i}\right)$. The observations with non-zero Langrage multipliers $\alpha_{i}$ are named as support vectors. The function used to predict new values depends only on support vectors and has the form:

$$
f(\mathbf{T})=\sum_{i=1}^{l}\left(\alpha_{i}-\alpha_{i}^{*}\right) \mathbf{K}\left(\mathbf{T}_{i}, \mathbf{T}\right)+b
$$

where: $\alpha, \alpha^{*}$ are non-negative Langrage multipliers for each observation $T$. Threshold $b$ can be derived from Langrage multipliers. In epsilon-insensitive regression ( $\varepsilon$-SVR), the training data set includes predictor variables $T$ and observed responds $y$ of the system. The aim is to find a function $f(T)$ that is derived from $y$ using a value no higher than $\varepsilon$ for each training point $T$ and at the same time so that this function was flat as much as possible. Non-linear SVM regression finds the Langrage coefficients by minimizing the following Langrage function [32]:

$$
L(\alpha)=\frac{1}{2} \sum_{i=1}^{l} \sum_{i=1}^{l}\left(\alpha_{i}-\alpha_{i}^{*}\right)\left(\alpha_{j}-\alpha_{j}^{*}\right) \mathbf{K}\left(\mathbf{T}_{i}, \mathbf{T}_{j}\right)+\varepsilon \sum_{i=1}^{l}\left(\alpha_{i}+\alpha_{i}^{*}\right)-\sum_{i=1}^{l} y_{i}\left(\alpha_{i}^{*}-\alpha_{i}\right)
$$


with constraints:

$$
\begin{gathered}
\sum_{i=1}^{l}\left(\alpha_{i}-\alpha_{i}^{*}\right)=0 \\
\forall i: 0 \leq \alpha_{i} \\
\forall i: 0 \leq \alpha_{i}^{*} \leq C
\end{gathered}
$$

In the optimization task, the Karush-KuhnTucker (KKT) complementary conditions, as the optimization constraints necessary to obtain optimal values of $\alpha$, should be met. The minimization problem can be solved using the QP techniques $[26,32]$.

\section{RESULTS AND DISCUSSIONS}

The two presented approaches for temperature modeling in annealing were applied on the experimentally measured data. Four experimental measurements on laboratory coil and two measurements on real coil were utilized for modeling. An approach based on the rules of non-stationary heat conduction and finite difference method was compared with the SVR. This section presents the results from the application of these approaches. The goal was to estimate the behavior of inner temperatures in the coil that was annealed.

\section{Software for modeling temperature field}

The essence of the software solution is a program that solves equation (11). The program calculates the temperature at each node of the inner matrix i.e., the grid of nodes (see Figure 6) (i.e., application on steel coil cutout). The node matrix has the size of $M \times N$.

The temperatures in marginal nodes of the matrix (i.e., edge points of the grid) are considered known at each time step of the simulation. These are the temperatures measured during the coil annealing in the experimental bell furnace. In each subsequent time step (i.e., step $k+1$ ), the temperatures of the nodes of the inner matrix are calculated from the known matrix temperatures from the previous time step (i.e., step $k$ ). This approach is called a solution at the boundary conditions of the 1st type. The designed program stores the matrices from all simulation time steps into both text and binary files, so the simulation can later be parsed and graphed.

All measured temperatures are stored in text files and in the directories named according to the selected sampling period (i.e., $1 \mathrm{~s}, 5 \mathrm{~s}$ or 30 s sam-

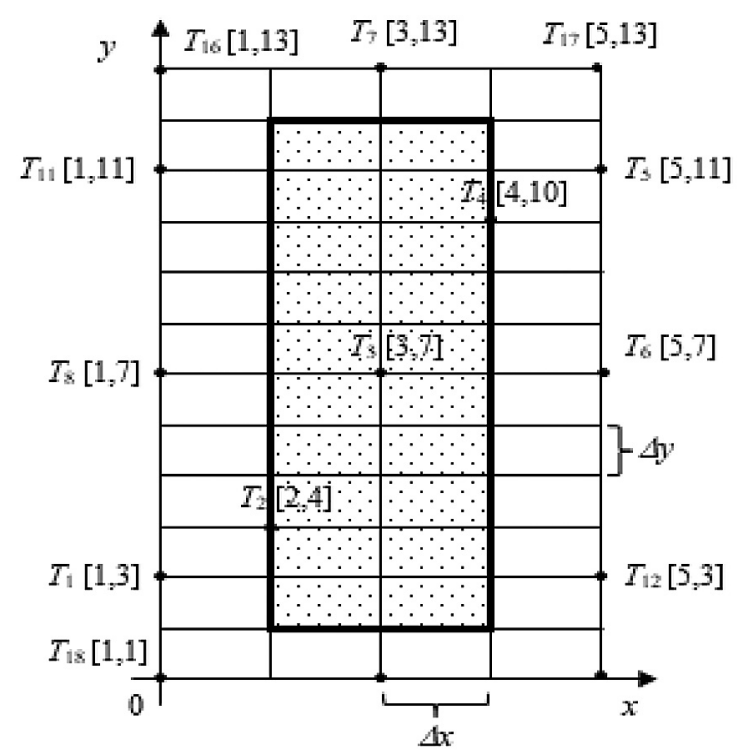

Fig. 6. Thermocouple positions on a physical model of the coil $(\Delta x=0.00375 \mathrm{~m}, \Delta y=0.00790 \mathrm{~m}, M=5$, $N=13)$

ples). The program allows selecting the source directory with the desired text files through the dia$\log$ box. For each thermocouple used then, there is a unique label that matches the name of the text file (e.g., T1.txt or T2.txt).

Figure 9 shows the positioning of thermocouples projected into the space of the temperature field (i.e., matrix or grid of nodes). This figure shows that the temperatures were measured not only at the edges of the coil (known marginal nodes) but even at some points inside the matrix. The measured temperatures inside the coil then served for checking model compliance with real measurement. Since all edge temperatures need to be known to calculate the temperatures in the inner matrix, and not measured at all temperature nodes, it was necessary to add an approximation algorithm of the marginal temperatures into initialization procedure. The linear approximation algorithm calculates the unknown temperatures (i.e., non-measured ones), e.g., $T_{11}, T_{12}$ from two known (i.e., measured) temperatures, e.g., $T_{10}$ and $T_{13}$. This procedure was applied wherever the temperature at the edge points was missing.

Figure 7 shows the main program window for modeling the temperatures in the temperature field. The program was written in the development environment of Embarcadero ${ }^{\circledR}$ RAD Studio using Delphi programming language (i.e., Object Pascal) using various visual components. The program was designed as an application for MS 
Windows. The main program window contains several tabs (i.e., Calculation, Matrix, Graphs, and Stability Condition); the user can switch between them. Next, the meaning of the individual tabs will be briefly explained for program usage. The first tab appears implicitly when the program is started and enables to set the initial simulation parameters and start the main calculation. At the top of the tab, there are edit boxes through which the user can change the dimensions of $\Delta x, \Delta y$, and the size of the time step $\Delta \tau$ of the simulation. It is also possible to specify the dimensions of the matrix as the number of nodes $M$ on the $x$-axis or the number of nodes $N$ on the $y$-axis. The last adjustable parameter is the simulation time, which represents the duration of the entire simulation. These parameters are only reflected in the calculations, which are much faster than the simulation time. On the Matrix tab, the user can view the matrix from any time step $k$. The

a.)

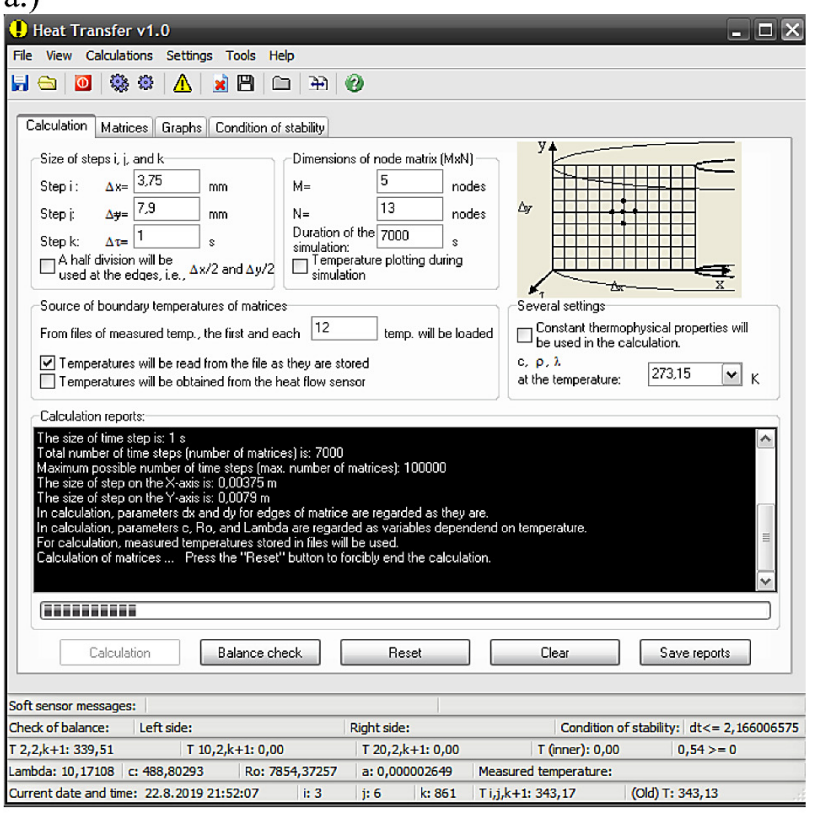

b.)

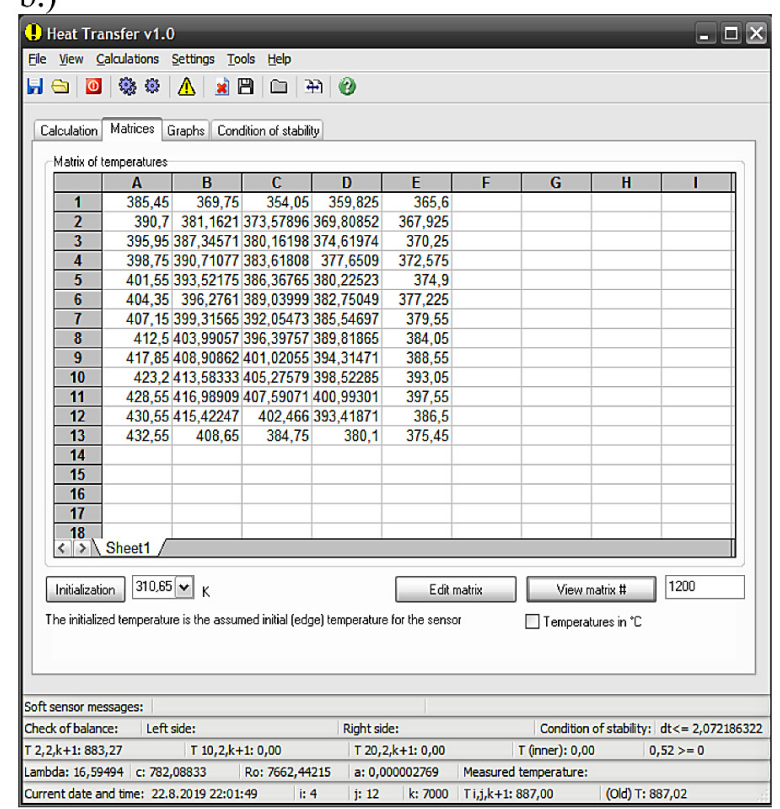

c.)

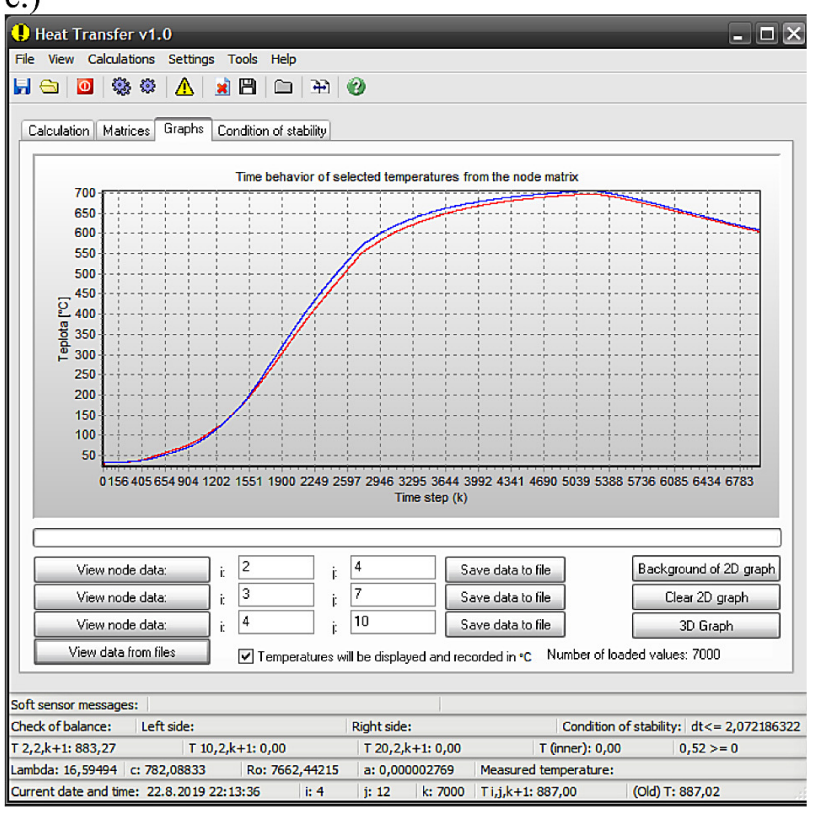

d.)

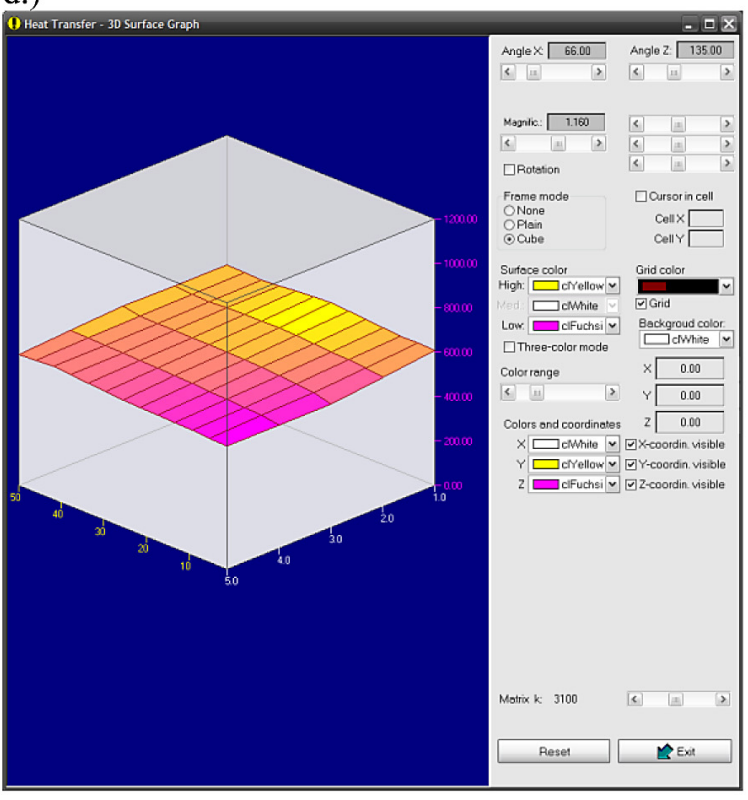

Fig. 7. a.) The main screen of the proposed application for modeling temperature field, b.) Matrix tab to display the calculated temperature field from a specific time step k, c.) Charts tab to display temperatures trends from the selected nodes (Legend: Blue line - temperature T2 measured by thermocouple, Redline - T2 estimated by model of nonstationary heat conduction), d.) Window of 3D plotting 
format of displayed temperatures can be changed for ${ }^{\circ} \mathrm{C}$ or $K$. On the Charts tab, the user can view the trend of any temperature at any position in the matrix (i.e., use View button). However, the coordinates of a given node should be provided. In this way, the user can view the trend of three selected points. For comparison of temperatures, the user can also display the measured temperatures of any node stored in a text file. The trend of the calculated temperature can be displayed after simulation, but the program also allows continuous plotting of temperature during the simulation. The temperature field can also be displayed as a 3D graph by pressing the 3D Graph button on the Charts tab. It is a 3D display of a two-dimensional temperature field where the temperature is displayed on the z-coordinate. There are special tools for graph rotation, color change, selection of the matrix shown, or graph increase in the 3D graph display window. The window for saving simulation in different ways is an essential tool in the program.

The simulation model should the predict quantitative information at least as accurately as it can be measured. In the case of the quantitative deficiencies of the simulation model, it is possible to adapt the simulation model using ambiguously determined input parameters of the model.

The task of adaptation is to minimize the quantitative deficiencies of the model to the required accuracy. In this case, the thermophysical properties of the steel (i.e., thermal diffusivity $a$, thermal conductivity $\lambda$, and specific heat of the steel $c$ ) in the model may be adapted. The adaptation algorithm is based on principle of the optimization method. The goal is to minimize the following objective function:

$$
F=\sum_{i=1}^{\tau_{k}}\left(T_{i}^{\text {meas }}-T_{i}^{\text {mod }}\right)^{2}
$$

where: parameter $T_{i}^{\bmod }$ represents the $i$-th value of temperature estimated by model and parameter $T_{i}^{\text {meas }}$ is the $i$-th value of the selected temperature (i.e., the check inner temperature) that was measured by thermocouple in the batch (i.e., steel coil). The parameter i represents the time step of the simulation $\left(i=1,2, \ldots, \tau_{k}\right)$ and $\tau_{k}$ is the total number of $\mathrm{T}^{\text {meas }}$ samples.

The core of the adaptation of selected thermophysical properties is the optimization algorithm, which is based on the principle of iterative dynamic programming (IDP) and the gradient method as discussed in the paper [9].
Several simulations were performed from experimental measurements on a laboratory coil (see Table 1) in the electric furnace. Two real coil measurements from real annealing plant were also available (see Table 5). In the data from a real annealing plant, the actual coil dimensions and specific matrix division were used. The match quality of the measured temperature and temperature calculated from the model was quantitatively expressed by the mean absolute percentage error (MAPE) (19) and by the maximum difference. In statistic, MAPE represents a measure of prediction accuracy of a forecasting method. It usually expresses precision as a percentage.

$$
\text { MAPE }=\frac{\sum_{k=1}^{n} \frac{\left|T_{k}^{\text {mod }}-T_{k}^{\text {meas }}\right|}{\left|T_{k}^{\text {meas }}\right|}}{n} \cdot 100(\%)
$$

where: $T_{k}^{\bmod }$ is the temperature calculated by model; $T_{k}$ meas is the measured temperature; $n$ is the total number of time steps from the simulation; $k$ is the time step $(k=1, \ldots, n)$.

\section{Results of soft-sensing based on non- stationary heat conduction}

The simulations of inner temperatures soft sensing were performed through the proposed Heat Transfer application (see Figure 7). This application solves equation (11) to calculate the temperature field in the steel coil. The simulations were performed on laboratory measurements and the measurements from the annealing plant. In this simulation, only the surface or rather bound-

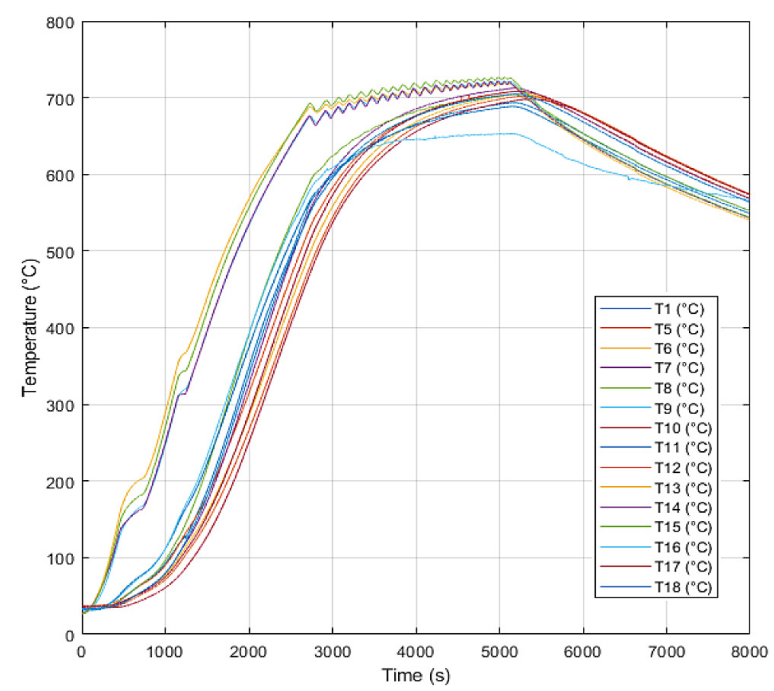

Fig. 8. Measured surface temperatures on laboratory coil from experiment \#2 
Table 1. Soft-sensor performance in laboratory measurements

\begin{tabular}{|c|c|c|c|}
\hline $\begin{array}{c}\text { Exp. } \\
\#\end{array}$ & Temp. & $\begin{array}{c}\text { MAPE } \\
\text { (\%) }\end{array}$ & $\begin{array}{c}\text { Max. difference } \\
\left.\text { ( }{ }^{\circ} \mathrm{C}\right)\end{array}$ \\
\hline \multirow{4}{*}{1} & $T_{2}$ & 4.40 & 35.38 \\
\cline { 2 - 4 } & $T_{3}$ & 6.83 & 59.85 \\
\cline { 2 - 4 } & $T_{4}$ & 4.33 & 30.95 \\
\hline \multirow{4}{*}{2} & $T_{2}$ & 2.45 & 23.50 \\
\cline { 2 - 4 } & $T_{3}$ & 3.20 & 27.48 \\
\cline { 2 - 4 } & $T_{4}$ & 3.12 & 13.80 \\
\hline \multirow{3}{*}{3} & $T_{2}$ & 5.03 & 51.46 \\
\cline { 2 - 4 } & $T_{3}$ & 3.86 & 26.99 \\
\cline { 2 - 4 } & $T_{4}$ & 2.31 & 13.80 \\
\hline \multirow{3}{*}{4} & $T_{2}$ & 7.73 & 61.12 \\
\cline { 2 - 4 } & $T_{3}$ & 4.51 & 29.57 \\
\cline { 2 - 4 } & $T_{4}$ & 1.80 & 15.40 \\
\hline
\end{tabular}

ary temperatures measured on the coils during experimental annealing were utilized as modeling inputs. Figure 8 shows surface, i.e. boundary temperatures measured by thermocouples during experimental laboratory annealing.

The results of simulations in four laboratory measurements are shown in Table 1. Designation of $T_{2}, T_{3}$, and $T_{4}$ is for thermocouples in nodes where the measured temperature was compared with the model. The designation of the thermocouples corresponds to the scheme shown in Figure 6.

Figure 9 shows a visual comparison of measurement and simulation conformity performed on a laboratory coil. The coil was heated in a laboratory furnace. The technical realization of the measurement was based on a PLC and a computer. In the figure, the blue line shows the measured temperature, and the red line represents simulated temperature (i.e., calculated). The MAPE found in this measurement was $1.80 \%$, and the maximum difference was $15.40^{\circ} \mathrm{C}$. The comparing temperature was measured by the thermocouple $T_{4}$, the placement of which inside the coil is demonstrated by the scheme in Figure 6 .

The results of simulations with the measurements on the real coil are shown in Tab. 2. The node matrix was regarded as shown in Figure 10. Two different measuring experiments were adopted from real annealing plants. In experiment $\# 1$, the diameters of coils were $1800 \mathrm{~mm}$, height $966 \mathrm{~mm}$ and weight was approximately $17 \mathrm{t}$. In this experiment, the temperature T11 (i.e., in Coil \#4) was modeled to its estimation in annealing In experiment \#2, the diameters of coils were 1600 $\mathrm{mm}$, height $966 \mathrm{~mm}$ and weight was approximately $18 \mathrm{t}$. In this experiment the temperatures T2 and T8 (i.e., Coil \#1 and Coil \#3) were modeled to its estimation in annealing.

The check thermocouples were placed on the position of modeled inner temperatures (similarly as in laboratory coil). The coils were bedded on each other on the stand. In the first experiment, four coils were bedded on each other, and in the second, only three coils were bedded. The convective rings were placed between coils. In the

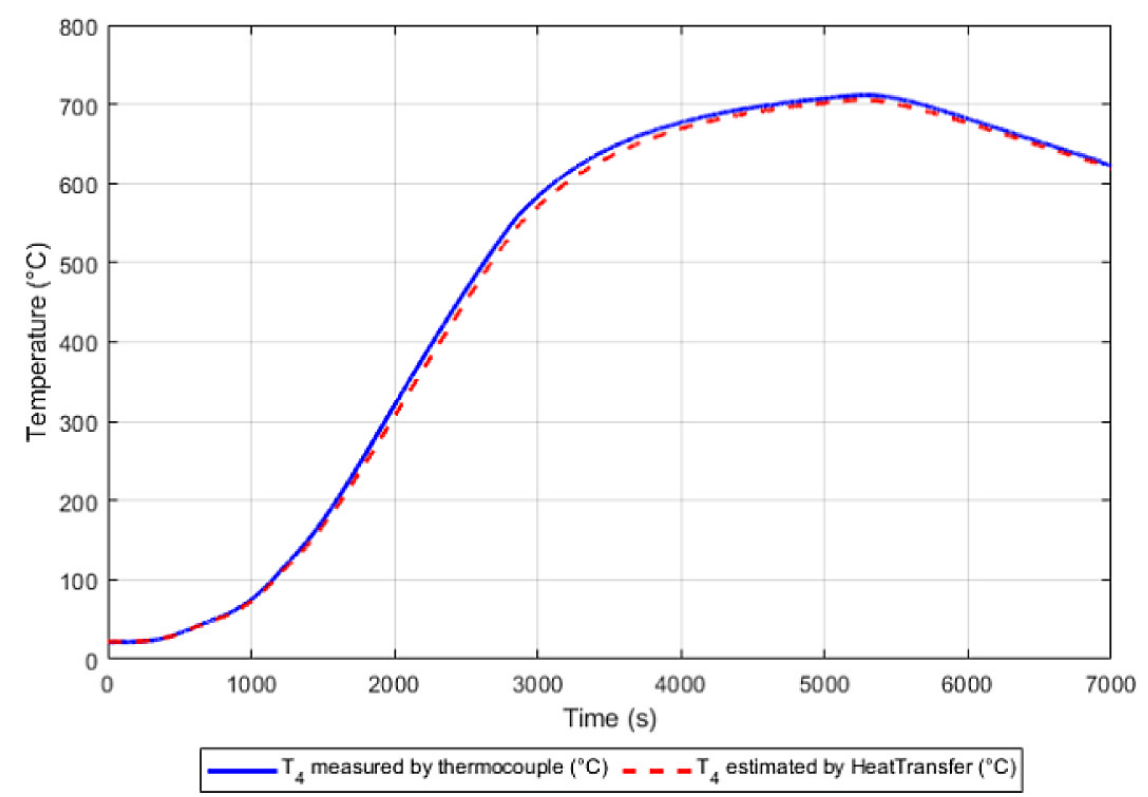

Fig. 9. Comparison of simulated and measured temperature $T_{4}$ on laboratory coil (experiment \#4) 
Table 2. Soft-sensor performance in real annealing measurement

\begin{tabular}{|c|c|c|c|}
\hline $\begin{array}{c}\text { Exp. } \\
\#\end{array}$ & Temp. & $\begin{array}{c}\text { MAPE } \\
(\%)\end{array}$ & $\begin{array}{c}\text { Max. difference } \\
\left({ }^{\circ} \mathrm{C}\right)\end{array}$ \\
\hline 1 & $\begin{array}{c}T_{11} \\
(\text { Coil \#4) }\end{array}$ & 5.40 & 48.97 \\
\hline 2 & $\begin{array}{c}T_{2} \\
(\text { Coil \#1) }\end{array}$ & 5.03 & 47.07 \\
\hline 2 & $\begin{array}{c}T_{8} \\
(\text { Coil \#3) }\end{array}$ & 2.19 & 23.80 \\
\hline
\end{tabular}

first experiment $T_{1}, T_{4}, T_{7}$, and $T_{10}$ were measured as the surface temperatures. Moreover, the temperature of annealing atmosphere, i.e., HNX mix gas was measured.

The results show that better performance of model based on nonstationary heat conduction was obtained in Experiment \#2 and temperature $T_{8}$ (see Table 2). Figure 11 shows the trend of the measured temperature inside the coil and the simulated temperature, which was calculated from the measured surface temperatures. The measurements were performed on a real steel coil from the annealing plant. The figure visually demonstrates the good match of measurement with simulation (i.e., the blue line is measured temperature and the red line is calculated, the simulated temperature respectively). The temperature $T_{8}$ inside the coil was also measured by the thermocouple. This temperature was compared with the modeled one. The truth of the conformity is also expressed quantitatively by the MAPE, which

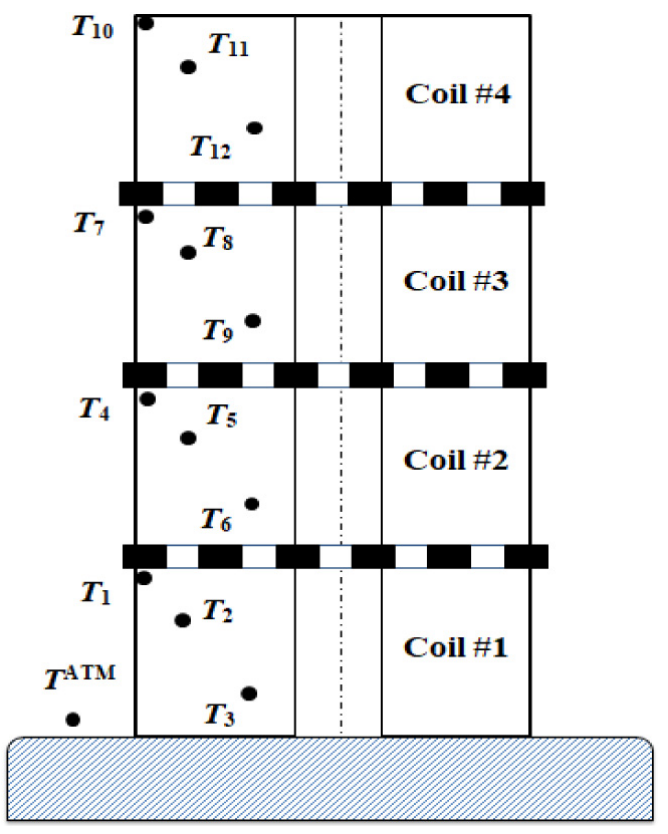

Fig. 10. Placement of thermocouples on four coils

in this case was only $2.19 \%$ and the maximum difference was $23.80^{\circ} \mathrm{C}$, which was found only during heating (i.e., at time $600 \mathrm{~min}$ ).

\section{Result of soft-sensing based on SVR}

Matlab Statistics, and Machine Learning toolbox [25] were used for SVR modeling of temperatures from batch annealing. A function fitrsvm (...) was used to create the SVR model and function

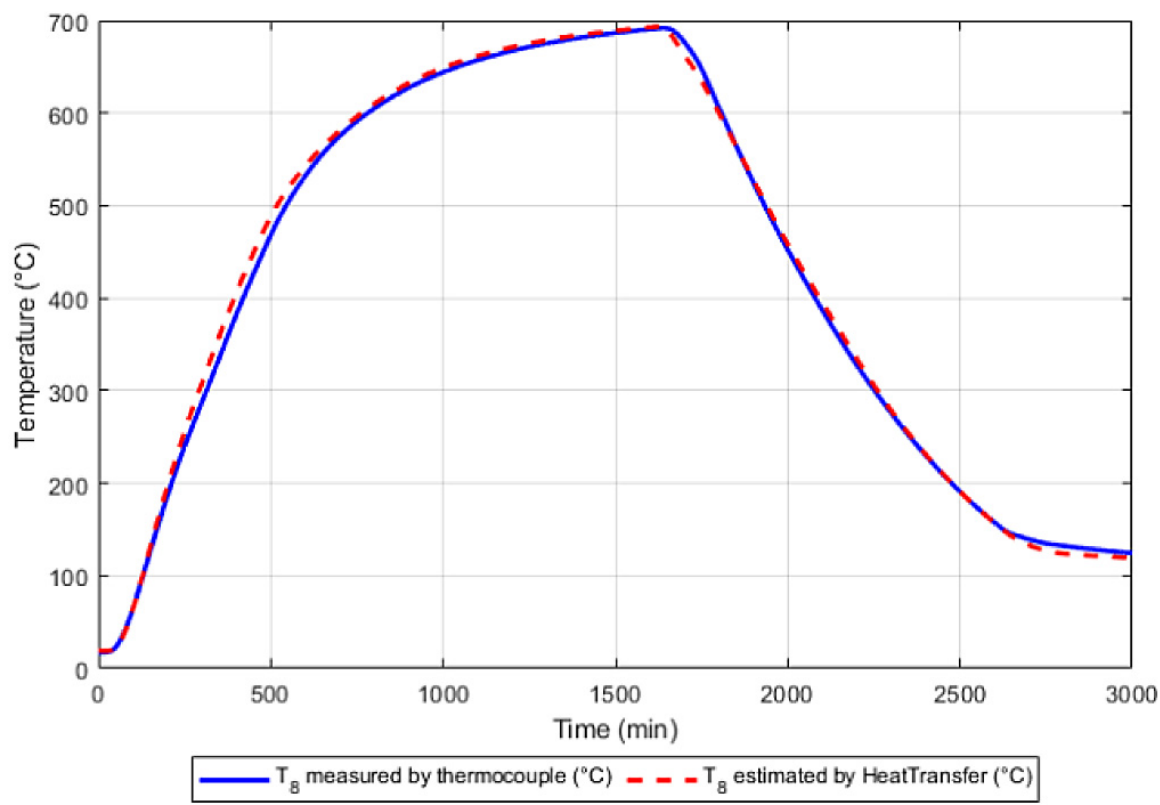

Fig. 11. Comparison of simulated and measured temperature $T_{8}$ on coil \#3 
predict (...) for the prediction. As an optimization method to solve (15) and (16) a Sequential Minimal Optimization (SMO) was used.

Several SVR models were created for temperatures modeling, i.e., for estimation of inner temperatures $T_{2}, T_{3}$ and $T_{4}$ for laboratory annealing. Similarly, separate machine models were created to estimate the inner temperatures $T_{2}, T_{8}$, and
$T_{11}$ for real annealing. In both cases, the boundary temperatures measured by thermocouple were considered as input observations and selected inner temperatures as targets. The target temperatures were also measured by thermocouples to create input-output pairs and train SVR models. Overall, four laboratory and two real annealing experiments (measurements) were modeled. a.)

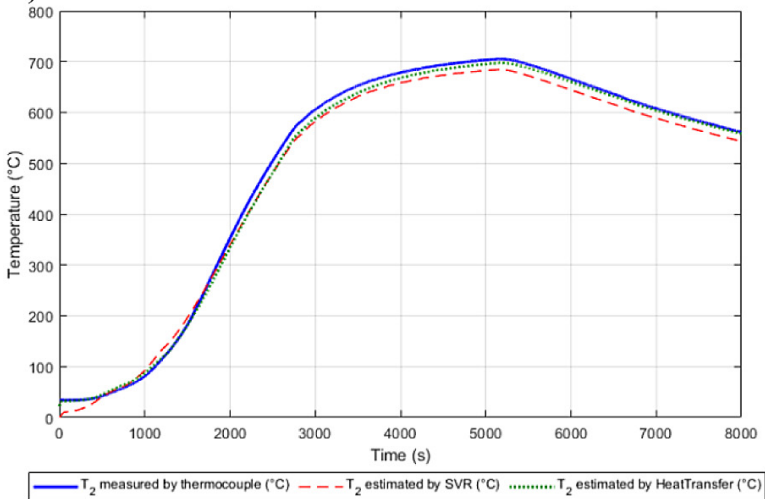

c.)

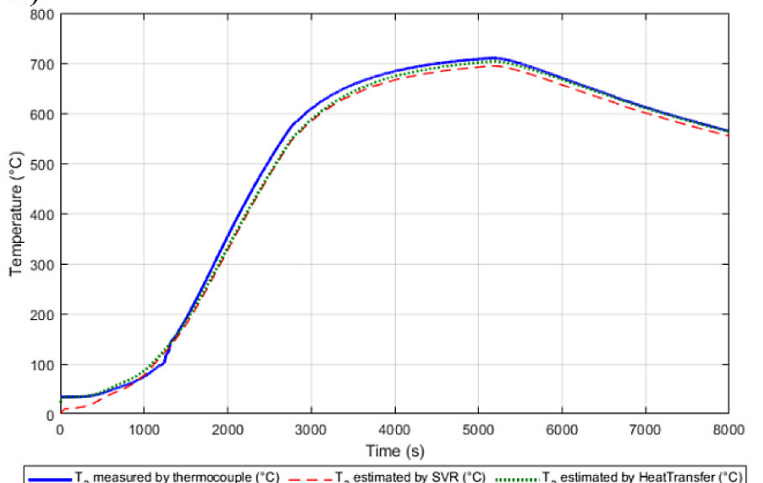

e.)

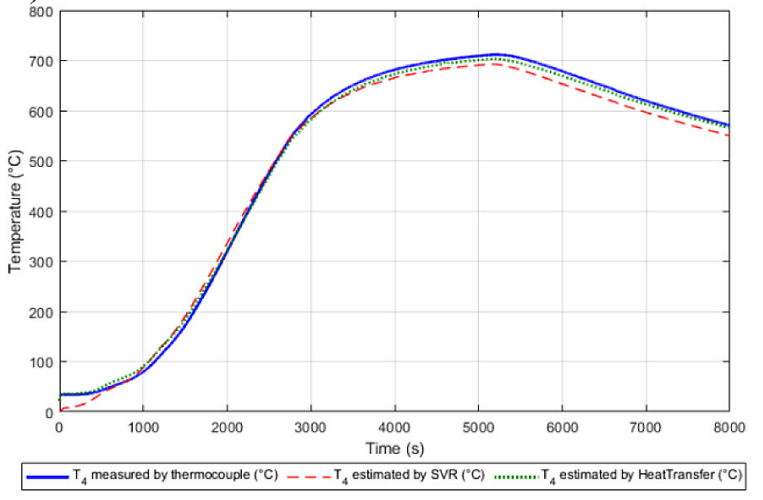

b.)

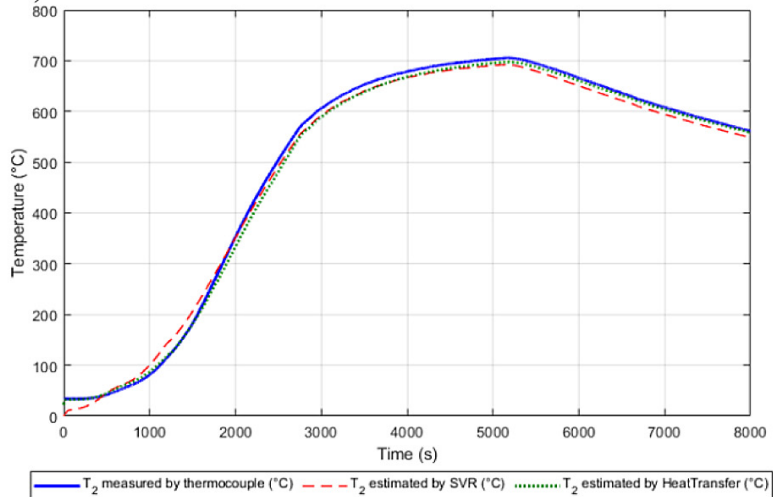

d.)

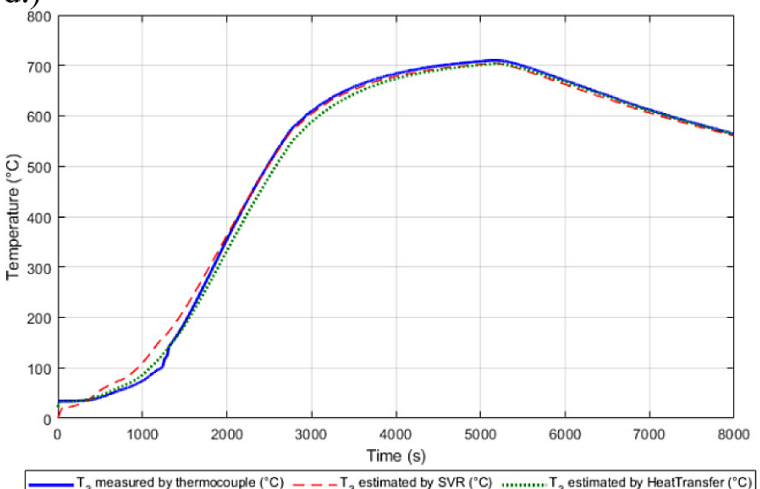

f.)

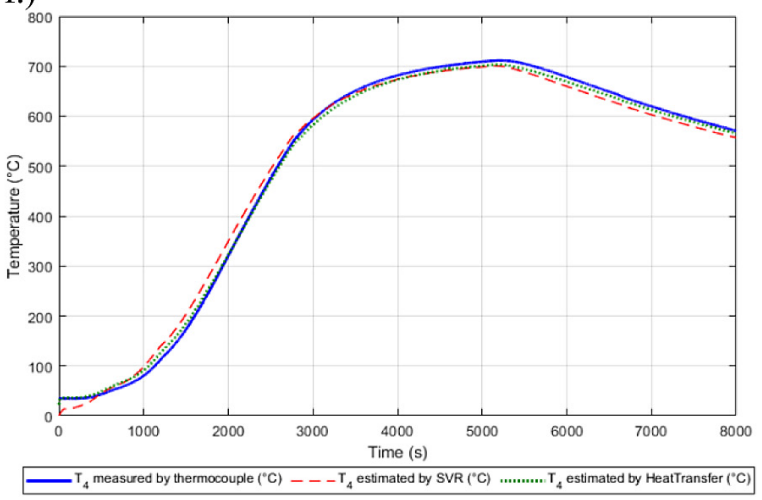

Fig. 12. Comparison of temperatures of Exp. \#2 measured by thermocouples, estimated by PC mode of heat conduction (Heat Transfer) and estimated by SVR (i.e., using Matlab) (a.) Measurement of $T_{2}$ where SVR model was trained only using observations of Exp. \#2, b.) Measurement of $T_{2}$ where the SVR model was trained using joined observations of Exp. \#1, \#3 and \#4, c.) Measurement of $T_{3}$ where SVR model was trained only using observation of Exp. \#2, d.) Measurement of $T_{3}$ where SVR model was trained using joined observations of Exp. \#1, \#3 and \#4, e.) Measurement of $T_{4}$ where SVR model was trained only using observation of Exp. \#2, f.) Measurement of $T_{4}$ where SVR model was trained using joined observations of Exp. \#1, \#3 and \#4) 
Seeing that the laboratory experiments were very similar and performed on the same coil, the strategy of the SVR models performance evaluation was proposed. In the laboratory experiments (measurements), the SVR models were trained and tested on the same data (i.e., from the same measurement). For example, when the model was trained on the data set of experiment \#1, testing of this model was also performed on this data set. Moreover, each model for the selected experiment was trained using the data from other experiments that were joined to one training data set. The testing of that model was performed on the data set (i.e., inner temperatures) that was not used in training. For example when a selected model was trained on the joined data set of experiments \#2, \#3 and \#4, it was tested on experiment \#1. This rule was applied to investigate the performance of the trained models (i.e., models of inner temperatures. In the modeling of laboratory data, only linear kernel was used, due to better-fitting of SVR models in compari- son with the Gaussian kernel. The results of the model performance for individual laboratory experiments and models are shown in Table 3. The values in parenthesis with an asterisk represent the results of model testing on the training data. Figure 12 shows the modeling results from experiment \#2. This figure shows the comparison of inner temperatures measured by thermocouple and temperatures estimated by SVR model and by the Heat Transfer application.

In modeling of inner temperature on the real coil, this rule of models evaluation was not applied due to the difference in experiments. Two real measurements (experiments) from real annealing were investigated. In the first experiment, four coils were bedded on each other and in the second experiment, only three coils were bedded on the stand for annealing. Moreover, the coils have different dimensions in individual experiments.

Seeing that in the real annealing experiments (measurements) the SVR models were trained and tested on the same data (i.e., from the same a.)

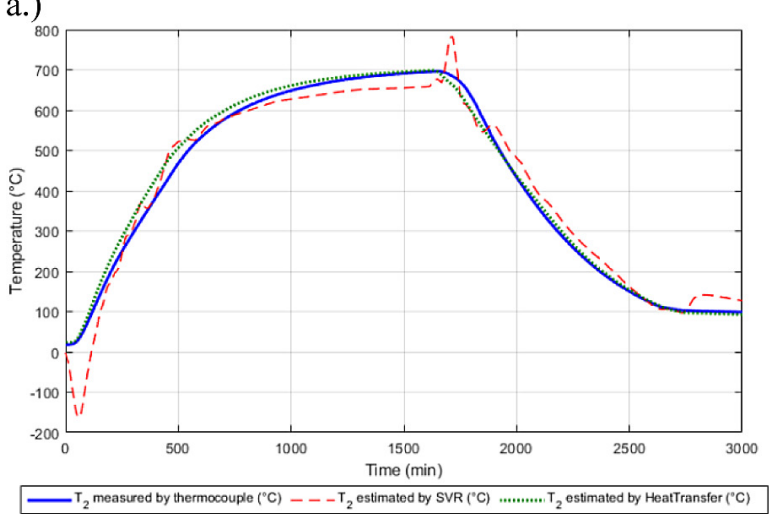

c.)

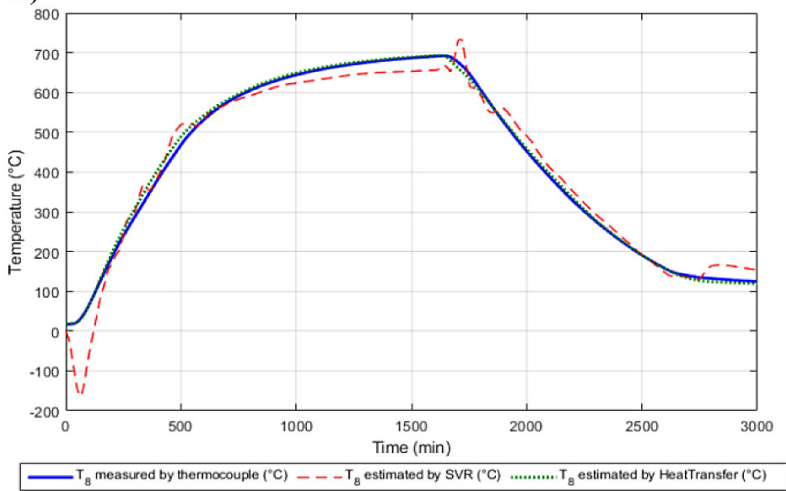

b.)

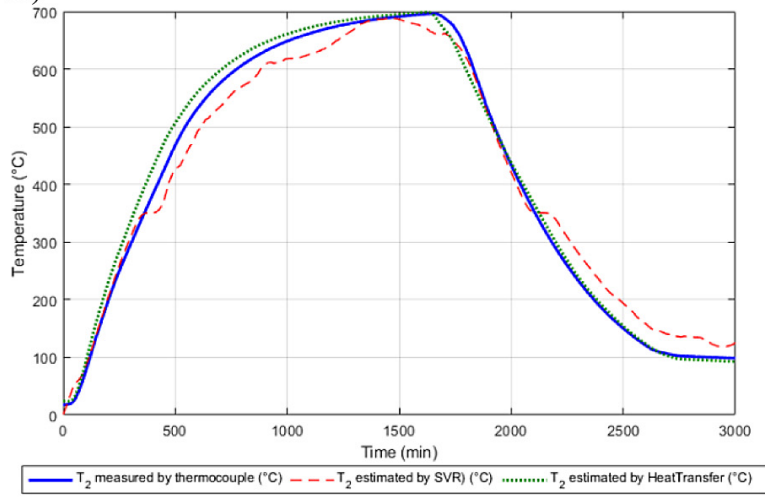

d.)

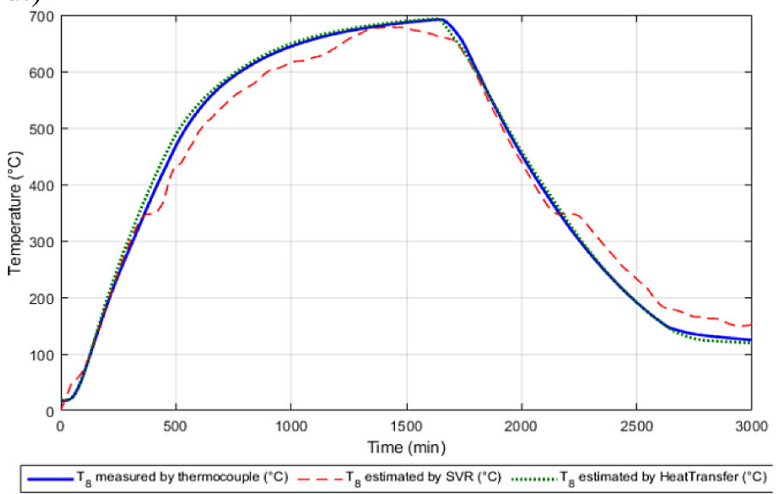

Fig. 13. Comparison of the temperatures measured by thermocouples, estimated by heat conduction model (Heat Transfer program) and estimated by SVR in real annealing experiment: a.) Exp. \#2, $T_{2}$ measurement, linear kernel, training and testing on Exp \#2. b.) Exp. \#2, $T_{2}$ measurement, Gaussian kernel, training and testing on Exp \#2. c.) Exp \#2, $T_{8}$ measurement, linear kernel, training and testing on Exp. \#2. d.) Exp. \#2, $T_{8}$ measurement,

Gaussian kernel, training and testing on Exp \#2 
measurements), but two different kernel functions were investigated (i.e., linear and Gaussian). The results of model performance for individual experiments and models are shown in Table 4.

The results show that better performance of SVR model was obtained in Experiment \#2 and temperature $T_{8}$. In SVR modeling, utilization of Gaussian kernel function reached the best results.

Figure 13 shows the modeling results from the measuring experiment \#2 of real annealing. This figure shows a comparison of inner temperatures measured by thermocouple and temperatures es-

Table 3. SVR model performance with linear kernel (*testing on training data)

\begin{tabular}{|c|c|c|c|}
\hline $\begin{array}{c}\text { Exp. } \\
\#\end{array}$ & Temp. & $\begin{array}{l}\text { MAPE } \\
(\%)\end{array}$ & $\begin{array}{l}\text { Max. difference } \\
\left({ }^{\circ} \mathrm{C}\right)\end{array}$ \\
\hline \multirow{3}{*}{1} & $T_{2}$ & $\begin{array}{c}13.13 \\
(10.17)^{*}\end{array}$ & $\begin{array}{c}32.51 \\
(28.91)^{*}\end{array}$ \\
\hline & $T_{3}$ & $\begin{array}{c}19.40 \\
(10.23)^{*}\end{array}$ & $\begin{array}{c}62.63 \\
(28.16)^{*}\end{array}$ \\
\hline & $T_{4}$ & $\begin{array}{c}12.48 \\
(8.99)^{\star}\end{array}$ & $\begin{array}{c}43.31 \\
(30.33)^{*}\end{array}$ \\
\hline \multirow{3}{*}{2} & $T_{2}$ & $\begin{array}{c}7.2 \\
(7.03)^{*}\end{array}$ & $\begin{array}{c}32.86 \\
(26.79)^{*}\end{array}$ \\
\hline & $T_{3}$ & $\begin{array}{c}8.26 \\
(6.08)^{*}\end{array}$ & $\begin{array}{c}60.93 \\
(23.99)^{*}\end{array}$ \\
\hline & $T_{4}$ & $\begin{array}{c}7.95 \\
(7.55)^{*}\end{array}$ & $\begin{array}{c}39.49 \\
(26.68)^{*}\end{array}$ \\
\hline \multirow{3}{*}{3} & $T_{2}$ & $\begin{array}{c}7.36 \\
(10.47)^{*}\end{array}$ & $\begin{array}{c}29.92 \\
(29.73)^{*}\end{array}$ \\
\hline & $\mathrm{T}_{3}$ & $\begin{array}{c}11.43 \\
(8.29)^{*}\end{array}$ & $\begin{array}{c}27.21 \\
(30.90)^{*}\end{array}$ \\
\hline & $\mathrm{T}_{4}$ & $\begin{array}{c}6.05 \\
(10.23)^{*}\end{array}$ & $\begin{array}{c}24.45 \\
(32.54)^{*}\end{array}$ \\
\hline \multirow{3}{*}{4} & $T_{2}$ & $\begin{array}{c}8.63 \\
(9.41)^{\star}\end{array}$ & $\begin{array}{c}31.45 \\
(28.79)^{*}\end{array}$ \\
\hline & $T_{3}$ & $\begin{array}{c}13.09 \\
(8.79)^{*}\end{array}$ & $\begin{array}{c}27.50 \\
(30.74)^{\star}\end{array}$ \\
\hline & $T_{4}$ & $\begin{array}{c}5.77 \\
(9.77)^{\star}\end{array}$ & $\begin{array}{c}19.03 \\
(32.62)^{*}\end{array}$ \\
\hline
\end{tabular}

Table 4. SVR model performance in real annealing

\begin{tabular}{|c|c|c|c|c|}
\hline $\begin{array}{c}\text { Exp. } \\
\#\end{array}$ & Temp. & $\begin{array}{c}\text { Kernel } \\
\text { function }\end{array}$ & $\begin{array}{c}\text { MAPE } \\
\text { (\%) }\end{array}$ & $\begin{array}{c}\text { Max. difference } \\
\text { (\%) }\end{array}$ \\
\hline \multirow{2}{*}{1} & $T_{11}$ & Linear & 25.07 & 113.34 \\
\cline { 3 - 5 } & $($ Coil \#4) & Gauss & 14.56 & 43.15 \\
\hline 2 & $T_{2}$ & Linear & 28.79 & 215.80 \\
\cline { 3 - 5 } & $($ Coil \#1) & Gauss & 14.77 & 35.64 \\
\hline \multirow{2}{*}{2} & $T_{8}$ & Linear & 27.33 & 210.57 \\
\cline { 3 - 5 } & $($ Coil \#3) & Gauss & 12.91 & 32.84 \\
\hline
\end{tabular}

timated by the SVR model and by Heat Transfer application (see previous subsections).

While comparing the results, it can be seen that an analytical solution based on non-stationary heat conduction is more accurate that SVR. It applies to both laboratory measurements and operational measurements.

The second approach based on SVR gave different results in testing of the SVR models on the training data of the same measurement (i.e., SVR models were tested only on data on which they were trained) and in testing models trained on different data set (i.e., from the various measuring experiments). In general, the SVR model well approximates the training data (see Table 3), i.e., values in parenthesis. When testing SVR models on data (measuring experiments) that were not included in the training data set, the models performance was lower (see values not in the brackets in the same tables). The performance of SVR models can be increased when the training dataset will be extended to more batch annealing experiments. This investigation was not possible in the operational measurements, because there were no more similar measurements available for training. The results of the simulation of SVR models on the operational measurements show that the use of the Gaussian kernel functions gave better accuracy (see Table 4). In this case, the SVR models were tested only on the data on which they were trained. The results show how the SVR models accurately approximate the operational data.

\section{CONCLUSIONS}

The existence of a soft-sensor as a measuring system will allow improving the product quality and reducing the energy consumption in energy-intensive technologies such as industrial furnace heating technology. The information on the temperatures in the annealed coil is essential to control the annealing plant and increase the production effectiveness. Because inner temperatures cannot be measured at each annealing, soft sensors based on mathematical models are being developed to cope with this problem. In this paper, soft sensing based on the rules of non-stationary heat conduction and support vector regression was investigated for the batch annealing process. Both approaches utilize the measured surface temperatures to estimate the inner temperature field. Moreover, the second approach 
has used the experimentally measured inner temperatures to train the SVR models. Both methods gave interesting results, but the first one was more accurate. The main advantage of the first proposed method based on non-stationary heat conduction is that the information on inner temperatures is not needed. However, the disadvantage of this approach is the requirement of optimized thermophysical properties for the given steel. The advantage of the second approach is that the complicated knowledge on heat conduction is not necessary. Support vector regression uses only the measured inputs and outputs and trains the model, i.e., optimize the support vectors based on training data. However, the main disadvantage is the requirement to measure these data and create a training data set (i.e., for various annealing regimes or dimensions of coils, more experimental measurements of surface and inner temperatures are needed).

Although the second approach was less accurate, it can provide a quick soft-sensing in monitoring system or serve as a complement for the analytical solution. Currently, the SVR is successfully implemented in many programming languages (e.g., Matlab, Python, C\#) as a standalone library of Machine Learning. The proposed program of the first approach can be used online or offline for soft-sensing temperature. The program also includes the algorithms for the calculation of thermal flows and algorithms for adaptation of thermo-physical parameters $\lambda$, c, and $\rho$. These algorithms are described in detail by the authors of this paper in other published papers. The presented approaches of soft-sensing were verified under laboratory conditions on a steel coil model and also on the measurements from real annealing plant. Further research will focus on soft-sensing of the surface temperatures.

\section{Acknowledgments}

This work was supported by the Slovak Grant Agency for Science under grant VEGA 1/0273/17, and by the Slovak Research and Development Agency under the contract No. APVV-18-0526.

\section{REFERENCES}

1. Bell Furnance Patents, RussianPatents.com. 2019. https://russianpatents.com/patent/217/ 2173718.html.

2. Bhadeshia, H. K. D. H. Neural networks in materials science. ISIJ International, 39(10), 1999, 966-979.
3. Boser, B. E., Guyon, I. M., Vapnik, V. N. A training algorithm for optimal margin classifiers. Proc. of the 5th Annual ACM Workshop on Computational Learning Theory - COLT'92 (Pittsburgh, PA, ACM Press), 1992, 144-152.

4. Col, M., Ertunc, H. M., Yılmaz, M. An artificial neural network model for toughness properties in microalloyed steel in consideration of Industrial production conditions. Materials and Design, 28(2), 2007, 488-495.

5. Corus. Corus Strip Products UK Finance Document Library. Cours Strip Products, UK, 2008.

6. Das, S., Singh, S. B., Mohanty, O. N., Bhadeshia, H. K. D. K. Understanding the complexities of bake hardening. Materials Science and Technology, 24(1), 2004, 107-111. https://doi. org/10.1179/174367507X247511.

7. Dehghani, K., Shafiei A. Predicting the bake hardenability of steels using neural network modeling. Materials Letters, 62(2), 2008, 173-178.

8. Durdán, M., Kačur, J. System for indirect measurement of the heat flows at annealing of the steel coils. Acta Metallurgica Slovaca 19(2), 2013, 112-121.

9. Durdán, M., Kačur, J., Laciak, M., and Flegner, P. Thermophysical Properties Estimation in Annealing Process Using the Iterative Dynamic Programming Method and Gradient Method, Energies, 12(3267), MDPI, 2019, 1-24. http://dx.doi. org/10.3390/en12173267.

10. Durdán, M., Mojžišová, A., Laciak, M., Kačur, J. System for indirect temperature measurement in annealing process. Measurement, 47(1), Elsevier, 2014, 911-918. http://dx.doi.org/10.1016/j.measurement.2013.10.013.

11. Durdán M, Stehlíková, B., Pástor, M., Kačur, J., Laciak, M., Flegner, P. Research of annealing process in laboratory conditions. Measurement. 73(1), Elsevier, 2015, 607-618. http://dx.doi.org/10.1016/j. measurement.2015.06.008.

12. Evans, P. J., Gutieerez, I, Petite, M. M., Larburu, J. I., Zaitegui, J., Hutchinson, W. B., Artymowicz, D., Spurr, G., Bhadeshia, H. K. D. H., Cheste, N. Modeling of Microstructural Development During Continuous Annealing Process. EU Report, ECSC 7210-EU/808, 1998.

13. Garrert, P. H. Neural network directed steel annealing, High Performance Instrumentation and Automation, CRC Press, 2005, 209-216. http://dx.doi. org/10.1201/ 9781420037357.ch12.

14. Haouam, A., Bigerelle, M., Merzoug, B. Simplex Enhanced Numerical Modeling of the Temperature Distribution in a Hydrogen Cooled Steel Coil Annealing Process. IX International Conference on Computational Heat and Mass Transfer, ICCHMT2016, Procedia Engineering, 157(1), Elsevier, 2016. 50-57. http://dx.doi.org/10.1016/j.proeng.2016.08.337. 
15. Chen, M. Y., Linkens, D. A., A systematic neurofuzzy modeling framework with application to material property prediction. IEEE Transactions on Systems Man Cybernetics Part B-Cybernetics, 31(5), 781-790.

16. Chen, M. Y., Linkens, D. A., Bannister, A. Numerical analysis of factors influencing Charpy impact properties of TMCR structural steels using fuzzy modelling. Materials Science and Technology, 20(5), 2004, 627-633.

17. Jones, D. M. The Modelling of Mechanical Properties of Steel from Processing Parameters at the Port Talbot Hot Strip Mill. Thesis submitted to Cardiff University for the degree of EngD, Cardiff University, Engineering Department. 2006.

18. Kačur, J., Durdán, M., Flegner, P., Laciak, M., Bogdanovská, G. Pulse-width modulation control of experimental bell furnace. International Multidisciplinary Scientific GeoConference Surveying Geology and Mining Ecology Management, SGEM 2018, Section Informatics, 649-656.

19. Kačur, J., Laciak, M., Durdán, M., Flegner, P. Utilization of Machine Learning Method in Prediction of UCG Data. In: 18th International Carpathian Control Conference (ICCC 2017), Sinaia, IEEE 2017, 278-283. http://dx.doi.org/ 10.1109/CarpathianCC.2017.7970411.

20. Kačur, J., Laciak, M., Flegner, P., Terpák, J., Durdán, M., Tréfa, G. Application of Support Vector Regression for Data-Driven Modeling of Melt Temperature and Carbon Content in LD Converter. 20th International Carpathian Control Conference (ICCC 2019), Krakow-Wieliczka, Poland, IEEE, 2019, 1-6. http://dx.doi.org/10.1109/CarpathianCC.2019.8765956.

21. Kostúr K., Process check of annealing process of coiled sheets by indirect measurement. Metalurgija, 56(1-2), 2017, 229-232.
22. Kostúr, K. Simulačné modely tepelných agregátov, Štroffek, Košice, 1997.

23. Kostúr, K., Laciak, M., Truchlý, M. Systémy nepriameho merania, Košice, TU Košice, 2005.

24. Llewellyn, D. T. Steels Metallurgy \& Applications. Butterworth-Heinemann Ltd., 1992.

25. MathWorks, Statistics and Machine Learning Toolbox (R2018b), The MathWorks Inc., 2018.

26. MathWorks, Understanding Support Vector Machine Regression, Statistics and Machine Learning Toolbox User's Guide (R2018b)., The Mathworks Inc., 2018.

27. Müller, K. R, Smola, A. J., Rätsch, G., et al. Predicting time series with support vector machines. In Lecture Notes in Computer Science (Springer Berlin Heidelberg), 1997, 999-1004.

28. Mojžišová, A., Kostúr, K. Model of indirect temperature measurement by neural network. Acta Montanistica Slovaca 13(1), 2008, 105-110.

29. Saraee, M. H., Moghimi, M., Bagheri, A. Modeling batch annealing process using data mining techniques for cold rolled steel sheets. University of Salford Manchester, UK, 2011, 18-22. http:// dx.doi.org/10.1145/ 2018673.2018677.

30. Takahashi, M., Okamoto, A. Effect of Nitrogen on Recrystallization Textures of Extra Low-Carbon Steel Sheet. Transactions of the Iron and Steel Institute of Japan, 19(7), 1979, 391-400.

31. Terpák, J., Dorčák, L. Procesy Prenosu. TU Košice, Faculty BERG, 2001.

32. Vapnik, V. N. Constructing learning algorithms. The Nature of Statistical Learning Theory (Springer Verlag, New York), 1995, 119-166.

33. Vlack Van L. H., Elements of Materials Science and Engineering (6th Edition). Pearson, 1989.

34. Wigley, N. R. Property Prediction of Continuous Annealed Steels. Thesis, Cardiff University, 2012. 